\title{
Identification of differentially expressed genes in skeletal muscle of non-diabetic insulin-resistant and insulin-sensitive Pima Indians by differential display PCR
}

\author{
Y. H. Lee ${ }^{1}$, S. Tokraks ${ }^{1}$, R. E. Pratley ${ }^{2}$, C. Bogardus ${ }^{1}$, P. A. Permana ${ }^{3}$ \\ ${ }^{1}$ Clinical Diabetes and Nutrition Section, Phoenix Epidemiology and Clinical Research Branch, \\ National Institute of Diabetes and Digestive and Kidney Diseases, National Institutes of Health, Phoenix, USA \\ 2 Department of Cardiovascular, Metabolic and Endocrine Clinical Research, Novartis Pharmaceutical Corp., East Hanover, \\ New Jersey, USA \\ ${ }^{3}$ Carl T. Hayden Veterans Affairs Medical Center, Phoenix, USA
}

\section{Abstract}

Aims/hypothesis. Whole body insulin resistance results largely from impaired insulin-stimulated glucose disposal into skeletal muscle. We carried out muscle gene expression profiling to identify differentially expressed genes associated with insulin resistance.

Methods. Skeletal muscle total RNA samples from six pairs of non-diabetic insulin-resistant and insulin-sensitive Pima Indians matched for percent body fat were analyzed by DDPCR with 90 primer combinations. The mRNA expression concentrations of selected 13 known genes and four expressed sequences tags were measured by quantitative real-time RT-PCR in 50 nondiabetic Pima subjects.

Results. From over 6500 displayed DDPCR cDNA bands, 36 of the most differentially expressed cDNAs were identified, revealing 29 unique sequences: 16 known genes, 10 expressed sequences tags and three unknown transcripts. Multiple regression analyses in- dicated that whole body insulin-mediated glucose disposal rates of the subjects, independent of age, sex, and percent body fat, were negatively correlated with mRNA concentrations of an EST (DD23; r $=-0.38$, $p=0.007)$, ATP1A2 ( $\mathrm{r}=-0.27, p=0.05), \mathrm{MAP} 2 \mathrm{~K} 4(\mathrm{r}=$ $-0.34, p=0.02)$, and PRPSAP1 $(\mathrm{r}=-0.37, p=0.008)$. Transcript concentrations of DD23 $(\mathrm{r}=0.27, p=0.05)$ and MTND4 $(r=-0.29, p=0.05)$ were correlated with plasma insulin concentration, independent of age, sex, and percent body fat.

Conclusion/interpretation. Altered expression concentrations of these genes might be causes or consequences of insulin resistance, and these genes serve as candidate susceptibility genes for insulin resistance. [Diabetologia (2003) 46:1567-1575]

Keywords Pima Indians, insulin resistance, Type 2 diabetes, skeletal muscle, gene expression, differential display, real-time PCR.
People with Type 2 diabetes are characterized by decreased action of insulin to mediate glucose disposal (insulin resistance), obesity, relatively reduced early insulin secretion, and excess rates of endogenous glucose production [1]. Prospective studies in Pima Indians of Arizona, a population with the highest reported

Received: 6 March 2003 / Revised: 3 July 2003

Published online: 24 October 2003

(C) Springer-Verlag 2003

Corresponding author: P. A. Permana, Carl T. Hayden Veterans Affairs Medical Center, ERS/151, 650 E. Indian School Road, Phoenix, AZ 85012 USA

Abbreviations: DDPCR, differential display PCR; IS, insulinsensitive; IR, insulin-resistant. prevalence of Type 2 diabetes [2], indicate that the first three of these metabolic characteristics are predictive of the disease [3].

Insulin resistance resulting from obesity contributes to the relationship between obesity and Type 2 diabetes $[4,5]$. Nevertheless, there is considerable variance in insulin action in vivo at any given degree of adiposity [6], and insulin resistance predicts the development of Type 2 diabetes independent of obesity in this population [3]. This obesity-independent variance in insulin action in vivo has considerable familial aggregation [7], indicative of possible primary genetic determinants. In contrast, insulin elicits many biological responses in various cell types, and hyperinsulinaemia associated with insulin resistance results in sec- 
Table 1. Clinical characteristics of six pairs of insulin-sensitive (IS) and insulin-resistant (IR) Pima Indian subjects for differential display experiment

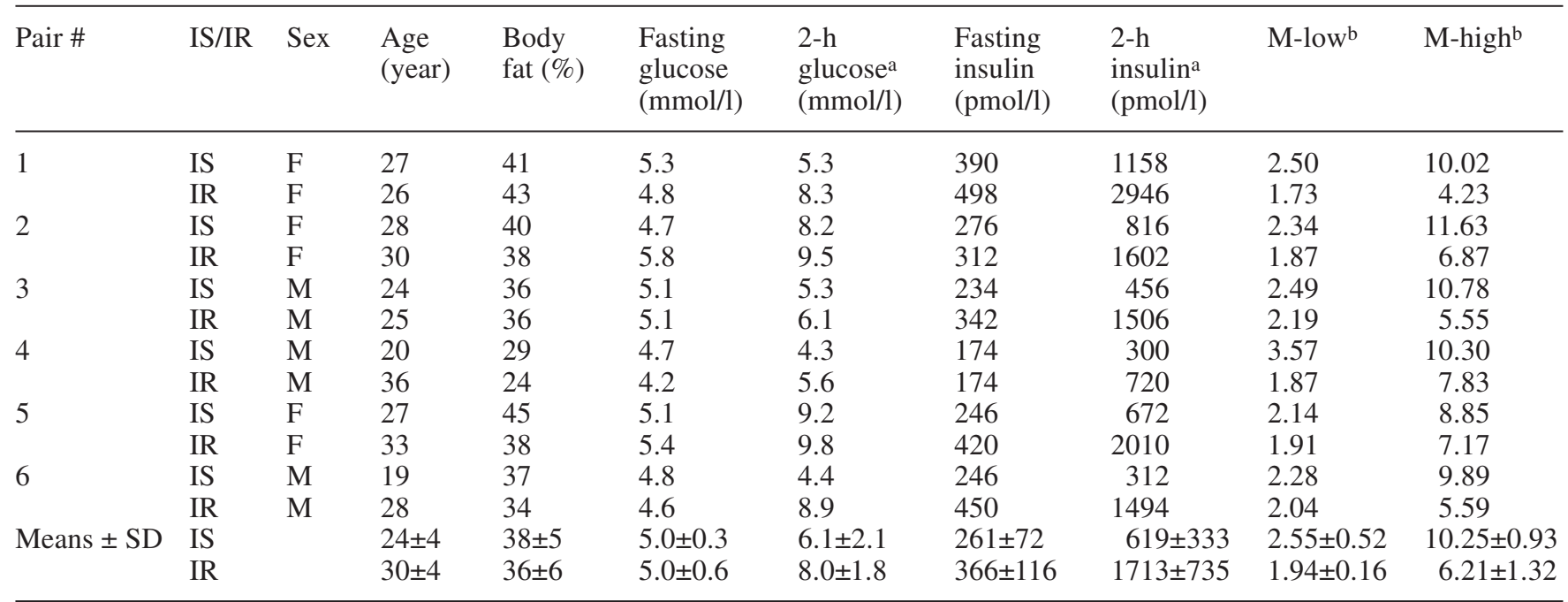

a 2 -h plasma glucose and insulin concentrations were measured 120 min after glucose administration during oral glucose tolerance tests

ondary effects. Both the primary (etiologic) genetic determinants and secondary effects of insulin resistance could be reflected in dysregulated transcription of genes contributing to the development and/or complication of the condition.

Since most of the insulin-mediated glucose uptake in the whole body is determined by insulin action on skeletal muscle [8], we compared concentrations of gene expression using differential display PCR (DDPCR) in skeletal muscle tissue samples from paired equally obese, insulin-sensitive and non-diabetic insulin-resistant Pima Indians to determine the transcripts that are over- or under-expressed in insulin-resistant subjects. This approach complements the global microarray profiling method on non-paired samples from a different set of insulin-sensitive and insulin-resistant Pima Indian subjects [9]. DDPCR uses random primers that could show the expression of transcripts that are not captured by the a priori design of the microarrays with defined sets of genes to interrogate.

\section{Subjects and methods}

Subjects and clinical procedures. This study was approved by the Tribal Council of the Gila River Indian Community and the Institutional Review Board of the National Institutes of Diabetes and Digestive and Kidney Diseases. All subjects provided written informed consent as participants in a longitudinal study of the development of Type 2 diabetes. They were in good health as determined by medical history, physical examination and routine blood and urine tests, and were not taking any prescribed or over-the-counter medication. Even though physical activity status was not measured in this study, the subjects were generally physically inactive. $\mathrm{b}$ insulin-stimulated glucose uptake rates $\left(\mathrm{mg} \cdot \mathrm{min}^{-1} \cdot \mathrm{kg}^{-1} \mathrm{EMBS}\right.$; EMBS, estimated metabolic body size determined from resting metabolic rate $=$ fat free body mass +17.7 ; [14]) at insulin infusion doses of 40 (M-low) or 400 (M-high) $\mathrm{mU} \cdot \mathrm{m}^{-2} \cdot \mathrm{min}^{-1}$

Table 2. Clinical characteristics of the 50 non-diabetic Pima Indian subjects for real-time RT-PCR and genotyping experiments

\begin{tabular}{lcc}
\hline Characteristics & Means \pm SD & Range \\
\hline Number (M/F) & $50(34 / 16)$ & \\
Age (year) & $30 \pm 7$ & $18-44$ \\
Body fat (\%) & $32 \pm 7$ & $9-43$ \\
Waist (cm) & $112 \pm 18$ & $71-157$ \\
Fasting glucose (mmol/l) & $4.9 \pm 0.6$ & $3.8-6.3$ \\
2-h glucose (mmol/l) & $6.7 \pm 1.9$ & $3.5-10.7$ \\
Fasting insulin (pmol/l) & $258 \pm 108$ & $114-606$ \\
2-h insulin (pmol/l) & $1056 \pm 750$ & $186-3972$ \\
M-low $^{\text {a }}$ & $2.62 \pm 0.84$ & $1.71-5.71$ \\
M-high $^{\text {a }}$ & $8.93 \pm 2.21$ & $4.23-13.68$ \\
\hline
\end{tabular}

a Insulin-stimulated glucose uptake rates $\left(\mathrm{mg} \cdot \mathrm{min}^{-1} \cdot \mathrm{kg}^{-1} \mathrm{EMBS}\right.$; EMBS, estimated metabolic body size determined from resting metabolic rate $=$ fat free body mass +17.7 ; [14]) at insulin infusion doses of 400 (high dose) or 40 (low dose) $\mathrm{mU} \cdot \mathrm{m}^{-2} \cdot \mathrm{min}^{-1}$

From the list of Pima Indian participants in the longitudinal study in whom glucose disposal rates had been measured using a two-step hyperinsulinaemic-euglycaemic clamp and skeletal muscle biopsies had been carried out, we selected pairs of subjects with the biggest difference in the measures of insulin sensitivity (based on glucose disposal rates) while matched for sex and per cent body fat as closely as possible. This selection resulted in six pairs of non-diabetic insulin-resistant and insulinsensitive subjects for the differential display PCR (DDPCR) experiment (Table 1).

Verification of selected differentially expressed genes was done using quantitative real-time RT-PCR on 50 subjects with a broad spectrum of insulin sensitivity. These subjects consisted of 8 of the 12 original subjects of the differential display experiment and additional 42 subjects (Table 2). 
Volunteers were admitted to the Clinical Research Unit for 8 to 10 days. They were fed a weight-maintaining diet (containing $50 \%$ of calories as carbohydrates, $30 \%$ as fat, and $20 \%$ as protein) for 2 to 3 days prior to metabolic testing. Body composition was measured by dual energy X-ray absorptiometry (DEXA) using a total body scanner (DPX-L, Lunar Radiation, Madison, Wis., USA) [10]. A 3-h 75 g OGTT was carried out after a 12-h overnight fast, and diabetes was defined according to the WHO criteria [11]. Insulin action was measured at physiologic and maximally stimulating insulin concentrations during a two-step hyperinsulinaemic-euglycaemic glucose clamp [3]. After an overnight fast, a primed continuous intravenous insulin infusion was administered for $100 \mathrm{~min}$ at a constant rate of $40 \mathrm{mU} \cdot \mathrm{m}^{-2}$ body surface area $\mathrm{min}^{-1}$ (M-low), followed by a second insulin infusion for $100 \mathrm{~min}$ at $400 \mathrm{mU} \cdot \mathrm{m}^{-2} \cdot \mathrm{min}^{-1}$ (M-high). These infusions achieved steadystate plasma insulin concentrations of $840 \pm 250 \mathrm{pmol} / \mathrm{l}$ and $13,320 \pm 3480 \mathrm{pmol} / \mathrm{l}$ (Means $\pm \mathrm{SD})$, respectively. Plasma glucose concentrations were maintained at $5.6 \mathrm{mmol} / \mathrm{l}$ with a variable infusion of a $20 \%$ glucose solution. Rates of insulin-stimulated glucose disposal at physiologic (M-low) and maximally stimulating (M-high) insulin concentrations were calculated for the last $40 \mathrm{~min}$ of each phase, and corrected for endogenous glucose output (EGO) [12]. During the low dose and baseline, EGO was calculated using a primed $(1.11 \times$ $\left.10^{6} \mathrm{~Bq} \cdot \mathrm{min}^{-1}\right)$, continuous $\left(1.11 \times 10^{4} \mathrm{~Bq} \cdot \mathrm{min}^{-1}\right) 3-{ }^{3} \mathrm{H}$-glucose infusion [3, 13]; during the high insulin dose, EGO was assumed to be zero. The glucose disposal rates during the clamp served as the selection criteria for insulin-sensitive or -resistant group. Subjects of similar percent body fat with highest or lowest glucose disposal rates were classified into the IS or IR group, respectively. All measurements derived from the glucose clamp were normalized to estimated metabolic body size (EMBS, which equals fat-free mass $+17.7 \mathrm{~kg}$ ) [14].

RNA isolation. Percutaneous needle biopsies were carried out on the vastus lateralis muscle under local anesthesia with $1 \%$ lidocaine after a 12-h overnight fast, and the biopsy specimens were immediately frozen in liquid nitrogen[15]. Total RNA was isolated from the frozen tissues homogenized in TRIzol Reagent (Life Technologies, Gaithersburg, Mass., USA).

Differential Display PCR. Differential display [16] was carried out as described in the Delta Differential Display kit user manual (Clontech, Palo Alto, Calif., USA). For the first screen, we used pooled equal quantities of total RNA from the IS vs the IR groups. Briefly, $4 \mu \mathrm{g}$ of total RNA was reverse-transcribed in $20 \mu \mathrm{l}$ reaction containing $1 \mathrm{mmol} / \mathrm{l} \mathrm{dNTP}, 0.1 \mu \mathrm{mol} / \mathrm{l}$ oligo (dT) primers and $400 \mathrm{U}$ of MMLV reverse transcriptase. Reverse transcription was carried out for $60 \mathrm{~min}$ at $42^{\circ} \mathrm{C}$ with a final denaturation step at $75^{\circ} \mathrm{C}$ for $10 \mathrm{~min}$. Aliquots of $4 \mu \mathrm{l}$ and $16 \mu \mathrm{l}$ from the resulting cDNA sample were diluted to $1: 10$ and 1:40. A $1 \mu \mathrm{l}$ of cDNA sample from each dilution was then amplified by PCR in a $20 \mu \mathrm{l}$ of total PCR reaction mixture including Advantage Klen Taq DNA polymerase (Clontech) and [33P] dATP (PerkinElmer Life Sciences, Boston, Mass., USA). We used one of nine anchored oligo(dT) primers and one of 10 arbitrary upstream primers provided in the kit, resulting in 90 primer combinations in total.

The cycling parameters were one cycle at $94^{\circ} \mathrm{C}$ for $5 \mathrm{~min}$, $40^{\circ} \mathrm{C}$ for $5 \mathrm{~min}, 68^{\circ} \mathrm{C}$ for $5 \mathrm{~min}$, two cycles at $94^{\circ} \mathrm{C}$ for $30 \mathrm{~s}$, $40^{\circ} \mathrm{C}$ for $30 \mathrm{~s}, 68^{\circ} \mathrm{C}$ for $5 \mathrm{~min}, 23$ cycles at $94^{\circ} \mathrm{C}$ for $20 \mathrm{~s}, 60^{\circ} \mathrm{C}$ for $30 \mathrm{~s}, 68^{\circ} \mathrm{C}$ for $2 \mathrm{~min}$ and a final extension at $68^{\circ} \mathrm{C}$ for $7 \mathrm{~min}$. The PCR products were separated on a polyacrylamide sequencing gel, SequaGel XR (National Diagnostics, Atlanta, Ga., USA). The gels were dried and exposed to Biomax MR film (Kodak, Rochester, N.Y., USA). Amplified cDNA bands with visually different signal intensities between the pooled IS vs IR samples were verified by differential display method in the six subject pairs individually. In this second screen, we determined a cDNA band to be differentially expressed if the signal intensity of that band visually differed in three or more of the six subject pairs.

Reamplification, cloning and sequencing. Differentially expressed PCR-bands were excised from dried gels, rehydrated in $40 \mu \mathrm{l} \mathrm{H}_{2} \mathrm{O}$ by boiling for $10 \mathrm{~min}$ and the eluted cDNA was reamplified by PCR using the same primer combination for 20 cycles in the presence of [ $\left.{ }^{33} \mathrm{P}\right]$ dATP. The reamplified cDNAs were separated again on a sequencing gel. After the second band recovery procedure, the reamplified cDNAs were cloned into the pT-Adv vector using the AdvanTage PCR Cloning kit (Clontech, Palo Alto, Calif., USA). Cloned cDNA fragments were sequenced with an ABI 377 or 3700 DNA sequencer using vector-specific T7 and M13 reverse primers and an ABI PRISM dye terminator cycle sequencing ready reaction kit (Applied Biosystems, Foster City, Calif., USA). We sequenced 10 to 30 representative clones of each transformed cDNA and the sequences were compared with the National Center of Biotechnology Information sequence database using the BLAST program.

Quantitative real-time RT-PCR. Quantitative real-time RT-PCR was carried out using the ABI PRISM 7700 Sequence Detection System (Applied Biosystems), according to the manufacturer's instructions. Primers and probes were designed using Primer Express (Applied Biosystems); the probes were labelled with FAM at the $5^{\prime}$ end and TAMRA at the $3^{\prime}$ end. Primers were obtained from Integrated DNA Technologies (Coralville, Ia., USA) and probes from Annovis (Aston, Penn., USA). The analyzed total RNA samples were reverse-transcribed using the Advantage RT-for-PCR kit (Clontech) after being treated with DNA-free reagent (Ambion, Austin, Tex., USA) to minimize potentially contaminating genomic DNA. The $25 \mu$ reaction mixture included cDNA template corresponding to $25 \mathrm{ng}$ of the original total RNA. Table 3 shows the sequences of the PCR primers and probes used in this experiment. PCR conditions were as follows: one cycle at $50^{\circ} \mathrm{C}$ for $2 \mathrm{~min}$, one cycle at $95^{\circ} \mathrm{C}$ for $10 \mathrm{~min}$, and 40 cycles at $95^{\circ} \mathrm{C}$ for $15 \mathrm{~s}$ and $60^{\circ} \mathrm{C}$ for $1 \mathrm{~min}$. The standard curves for each gene were generated by serial dilution of cDNA from a skeletal muscle biopsy of a healthy Pima subject. Messenger RNA expression of each gene was normalized to that of human cyclophilin (Pre-developed Taqman Assay Reagents Endogenous Control Human Cyclophilin kit, Applied Biosystems), a normalizing gene previously utilized [9] that had similar abundance to the target genes. As a normalizing gene, cyclophilin was shown to give similar results to the more abundant $18 \mathrm{~S}$ rRNA [17].

Statistical analysis. Statistical analyses were carried out using the statistical analysis system of the SAS Institute (Cary, N.C., USA). For continuous variables, general linear regression models were used to adjust for the effects of age, sex, and percent body fat. Plasma insulin concentrations and rates of glucose disappearance during the low-dose insulin infusion were $\log$ transformed to approximate normal distribution. The mRNA expression concentrations of the genes were normalized to that of human cyclophilin by taking their residuals from linear regression analysis. A $p$ value less than or equal to 0.05 (unadjusted for multiple testing) was considered statistically significant. 
Table 3. Probes and primers used in quantitative real-time RT-PCR

\begin{tabular}{|c|c|c|c|}
\hline & Forward primer & Reverse primer & Probe \\
\hline ATP1A2 & gegttggctgcctttctct & cgcagaaccaccaggtgact & tagccetccgcatgtacccgctc \\
\hline$A T P 5 A 1$ & ggtcgtggtcagcgtgaact & cgtttctggttaatgattgtgtcaa & accgacagactgggaaaacctcaattgc \\
\hline$M B N L$ & ccatggtgcacggtgcta & gcagcgaagggaacacttg & agccactgtgtccgcagcaacaac \\
\hline$M T C Y B$ & ctcctaggcgacccagacaa & ggacggatcggagaattgtg & accetagccaacccettaaacacccet \\
\hline MTND3 & cgtccetttctccataaaattcttc & ccagacttagggctaggatgatga & tgccetccttttaccctaccatgagc \\
\hline PRPSAP1 & cccagtcctatgcggagagac & gttccgtgcactgagcttcc & cgtctgggtttggccgtcattcac \\
\hline PSAP & gccotgctgatcgagat & cttgggccccatatacacttct & tggatccttccttcgtgtgcttgaaaat \\
\hline TNNC1 & ggacggagacaagaacaacga & caggactcagctggagttgga & tgaccttcacccagagctgcctatgc \\
\hline TPII & ggccattggtactggcaaga & ccgcatcagagacgttgga & tgcaacacccaacaggcca \\
\hline FLJ10326 & gggtagctgattccaatgtcttc & tgctaatatcatctctggcagcat & aagttgcaattggcccatccgtgc \\
\hline DD11 & agacaattcttcttccagtgtgtcc & gaagattcagattcagtggtgctg & agatgatagtcaggccacagctctgctcac \\
\hline
\end{tabular}

* All sequences are listed from $5^{\prime}$ to $3^{\prime}$

\section{Results}

Differential Display PCR. We carried out the first differential display screen on pooled total RNA samples of six insulin-sensitive (IS) subjects and pooled samples of matched six insulin-resistant (IR) subjects using 90 primer combinations. There were 78 differentially expressed bands from over $6500 \mathrm{cDNA}$ bands displayed. Out of the 78 cDNA bands, we selected 36 bands that had visually different signal intensities in three or more of the six subject pairs in the second differential display screen using individual RNA samples. To identify these transcripts, each band was cut from dried gel, rehydrated, reamplified with corresponding primer set, and an additional band isolation step was performed (Fig. 1).

The 36 differentially expressed cDNAs were individually cloned and sequenced. Sequencing analysis of the clones identified 29 unique sequences; 16 of them matched with more than $95 \%$ sequence identity to known genes (ATP1A2, ATP5A1, HBB, MAP2K4, MBNL, MTCO2, MTCYB, MTND3, MTND4, MYBPC1, PRPSAP1, PSAP, RY-1, TNNC1, TPI1, and FLJ1032; Table 4) and 13 sequences (10 ESTs and 3 unknown) did not show any homologies to any known genes.

During the sequencing analysis of the clones, we found $9 \mathrm{bp}, 7 \mathrm{bp}$ and $6 \mathrm{bp}$ deletion polymorphisms in MTCO2, RY-1, and an EST on chromosome 17, respectively. The first two polymorphisms resulted in heterozygotic cDNA band patterns in the sequencing gels of differential display (Fig. 2), whereas the polymorphic EST showed a typical pattern of differentially expressed cDNA with varying intensity across samples. To determine whether these deletions are associated with insulin resistance, we genotyped the polymorphisms by PCR method in 50 non-diabetic Pima

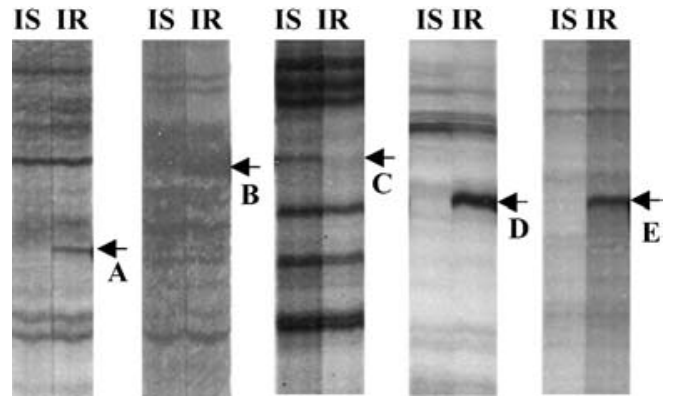

Fig. 1A-E. Representative DDPCR bands corresponding to differentially expressed genes. Sample lanes from insulin-sensitive (IS) and insulin-resistant (IR) subjects are indicated. Arrows show differentially expressed DDPCR bands between an IS-IR pair for (A) DD23, (B) ATP1A2, (C) MAP2K4, (D) MTND4, and (E) PRPSAP1

Indians including 8 of the 12 original samples of the differential display. The PCR was conducted using skeletal muscle cDNAs with allele specific primer sets for each gene, and the PCR products were electrophoresed in $2 \%$ agarose gels. The mean values of several measures of insulin resistance (fasting and 2-h plasma insulin concentrations, and glucose disposal rates during the hyperinsulinaemic euglycaemic clamp) did not differ statistically among the different genotype groups of the polymorphisms (data not shown).

Extension of selected DDPCR results in a larger sample set. We sought to extend the DDPCR results using Real Time RT-PCR in a larger sample set of 50 non-diabetic Pima subjects including 8 of the 12 original samples used for the differential display. Out of the 16 known genes with differential expression as assessed by DDPCR, we chose to validate the expression concentra- 
Table 4. Differentially expressed genes with known functions identified by DD-PCR in six pairs of non-diabetic insulin-resistant and insulin-sensitive Pima Indians

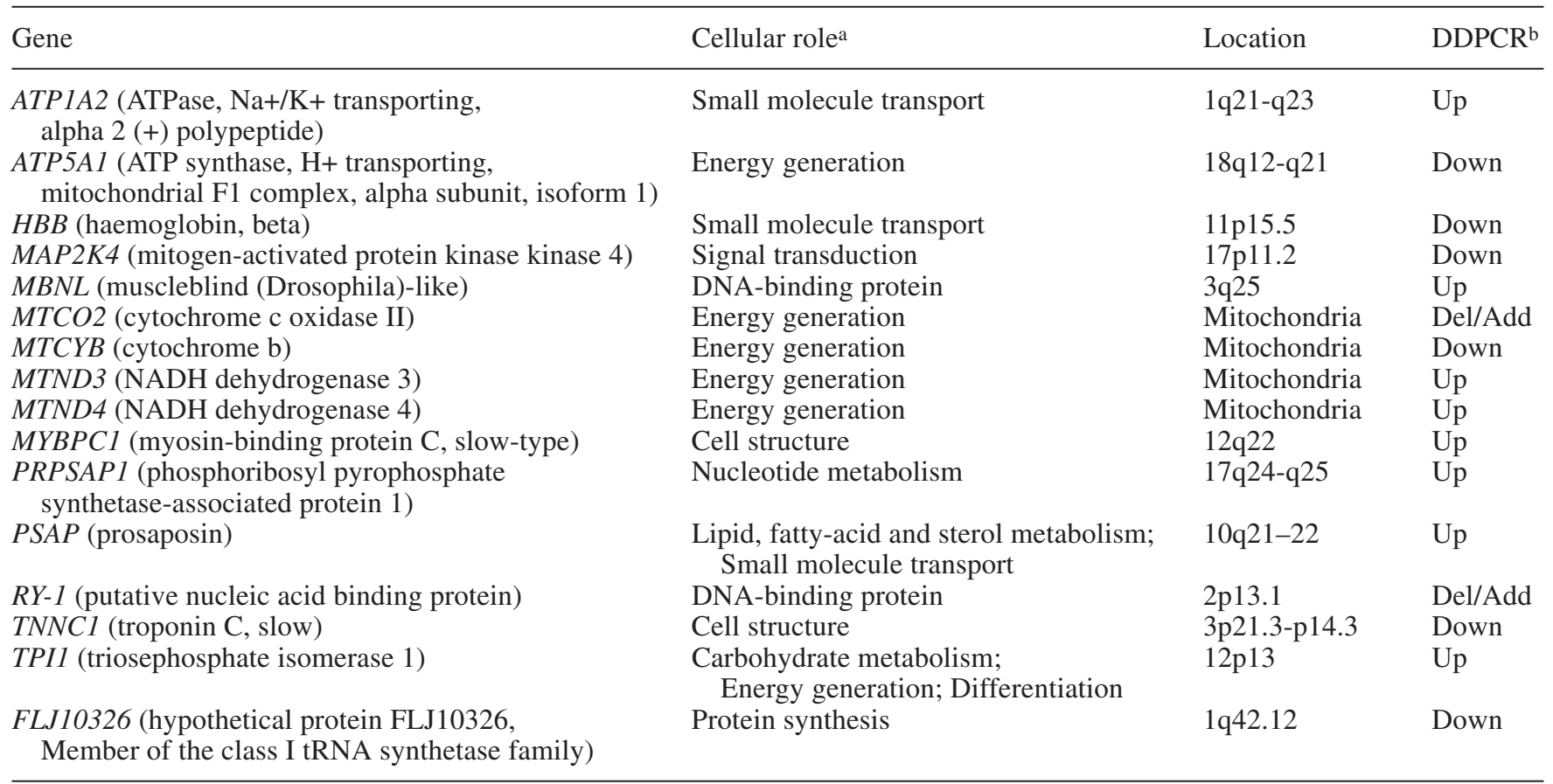

a Human Proteome Survey Database (HumanPSD) (Incyte Genomics, Beverly, Md., USA)

b Up- or down-regulated in insulin resistant subjects

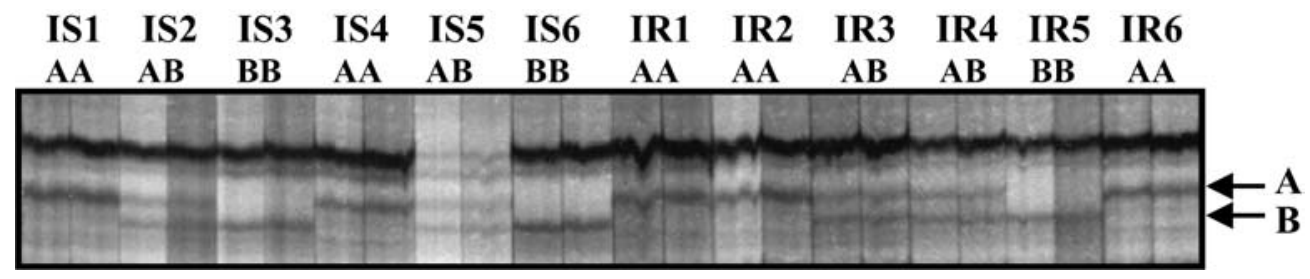

Fig. 2. Distinguished heterozygotic cDNA band patterns in DDPCR of the RY-1 gene with seven base pairs (bp) deletion mutation in six IS-IR subject pairs. All reactions were carried out in duplicate and loaded on two gel lanes. Band products of "A" and "B" were isolated, cloned, and sequenced. Both cDNA bands turned out to be transcript variants of the RY-1 gene with 7 bp difference. These genotypes were confirmed by PCR with allele specific primers using cDNAs from all six subject pairs

tions of 13 genes that were expressed in muscle at least as abundantly as in some other tissues according to GeneCard database (http://nciarray.nci.nih.gov/cards/). The 13 selected genes were ATP1A2, ATP5A1, TNNC1, TPI1, PSAP, MBNL, MYBPC1, MTCYB, PRPSAP1, $M A P 2 K 4, M T N D 3, M T N D 4$, and FLJ10326. We excluded $M T C O 2$ and $R Y-1$, since their differentially expressed cDNA bands were due to deletion mutation, and $H B B$ that was most highly expressed in bone marrow. Out of the 13 differentially expressed ESTs in DDPCR, we further investigated four ESTs with the biggest visual differences between the IR and the IS pairs. Gene-
Bank accession numbers of the four ESTs (DD11, DD14, DD23, and DD24) are AI204632, BE173380, BG436275, and W58230, respectively.

Multiple regression analysis using adjustments for age, sex, and percent body fat indicated that glucose disposal rates at physiological insulin concentration during clamp were negatively correlated with individual mRNA concentrations of DD23, ATP1A2, MAP2K4, and PRPSAP1 (Table 5 and Fig. 3). The MAP2K4 transcript concentration was also negatively correlated with glucose disposal rate at maximally stimulating insulin concentration during clamp. Additionally, fasting plasma insulin concentration was positively and negatively correlated with transcript concentrations of DD23 and MTND4, respectively (Table 5).

\section{Discussion}

Our study revealed differentially expressed genes in skeletal muscle of insulin-resistant human subjects that could constitute primary causes or secondary effects of this condition. Identification of abnormal skel- 


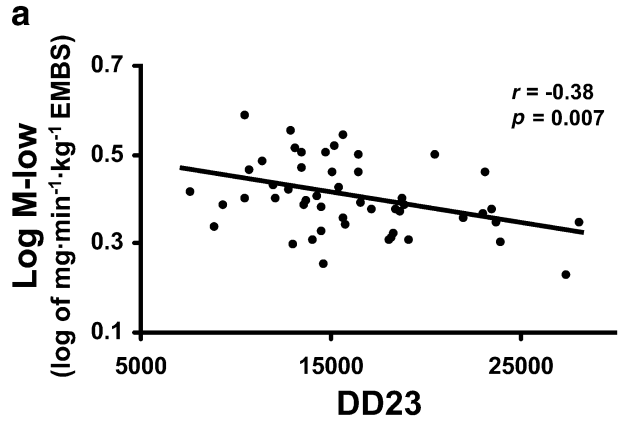

(Relative expression units)

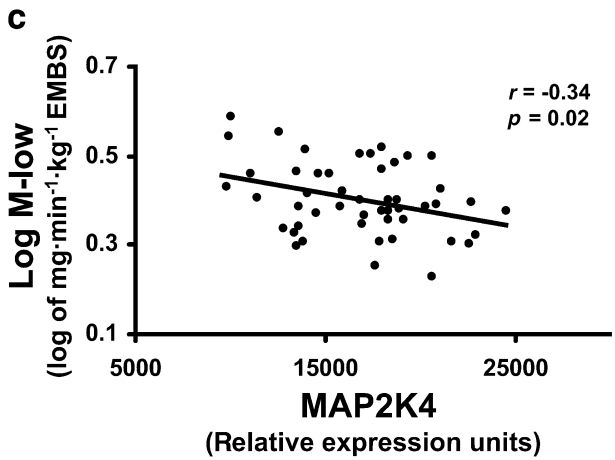

Fig. 3A-D. Relationships between glucose disposal rates at physiological insulin concentration during clamp (M-low) and expression levels of (A) DD23, (B) ATP1A2, (C) MAP2K4, and (D) PRPSAP1. M-low was adjusted for age, sex, and percent body fat, and each gene expression was normalized to that of cyclophilin

Table 5. Significant correlations of five skeletal muscle mRNA transcripts with adjusted clinical parameters of 50 nondiabetic Pima Indians

\begin{tabular}{lccccc}
\hline & & M-low & M-high & $\begin{array}{c}\text { Fasting } \\
\text { insulin }\end{array}$ & 2-h insulin \\
\hline DD23 & $\mathrm{r}$ & -0.38 & -0.24 & 0.27 & 0.17 \\
& $p$ & $\mathbf{0 . 0 0 7}$ & 0.09 & $\mathbf{0 . 0 5}$ & 0.2 \\
ATP1A2 & $\mathrm{r}$ & -0.27 & -0.15 & 0.13 & 0.10 \\
& $p$ & $\mathbf{0 . 0 5}$ & 0.3 & 0.4 & 0.5 \\
MAP2K4 & $\mathrm{r}$ & -0.34 & -0.31 & 0.11 & -0.10 \\
& $p$ & $\mathbf{0 . 0 2}$ & $\mathbf{0 . 0 3}$ & 0.5 & 0.5 \\
MTND4 & $\mathrm{r}$ & 0.12 & -0.03 & -0.29 & -0.07 \\
& $p$ & 0.4 & 0.8 & $\mathbf{0 . 0 5}$ & 0.6 \\
PRPSAP1 & $\mathrm{r}$ & -0.37 & -0.17 & 0.19 & -0.14 \\
& $p$ & $\mathbf{0 . 0 0 8}$ & 0.2 & 0.2 & 0.4 \\
\hline
\end{tabular}

$p$ value of multiple regression analysis after adjustment for age, sex, and percent body fat; $p$ values $\leq 0.05$ are in bold

etal muscle gene expression associated with insulin resistance is important in elucidating the pathogenesis of this condition. Altered gene expression in insulin resistance can be considered molecular markers that could lead to a better understanding of the functions of the genes in the progressive metabolic impairment.
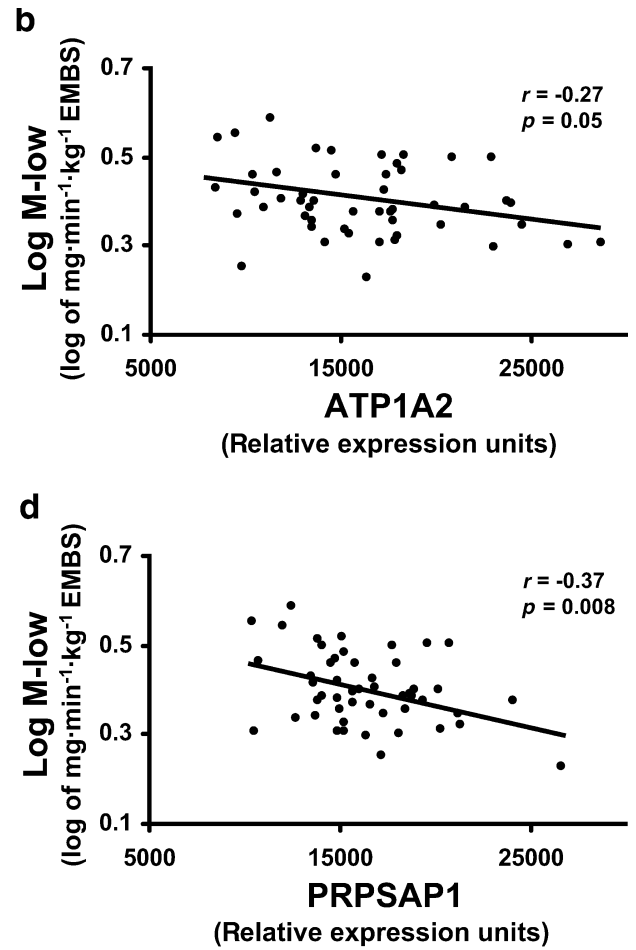

To this end, we applied mRNA Differential Display PCR techniques to identify differentially expressed genes in skeletal muscle tissues of six pairs of non-diabetic insulin-resistant and insulin-sensitive Pima Indians. To eliminate potential confounding complications from diabetes, we selected non-diabetic subjects with the biggest difference of glucose disposal rates as a measure of insulin sensitivity. Apart from being matched for sex, the paired subjects were also matched for percent body fat to minimize differences resulting from obesity. The effort to match each subject pair for percent body fat, especially in the Pima population that is generally obese, resulted in a collectively small $(24 \%)$, though significant $(p=0.03)$, difference of glucose disposal rate at physiological concentration of insulin during the clamp. Nevertheless, the collective average differences in other measures of insulin sensitivity were bigger and significant: $39 \%$ ( $p=0.002)$ for glucose disposal rates at maximally stimulating insulin concentration as well as $29 \%$ $(p=0.02)$ and $64 \%(p=0.002)$ for fasting and 2-h plasma insulin concentrations post oral glucose bolus intake, respectively.

The DDPCR approach revealed 29 unique genes that are most differentially expressed in these samples; $45 \%$ of these transcripts are ESTs of unknown genes. The identified known genes are involved in energy metabolism, signal transduction, and cell structure. Verification of differential gene expression after mRNA Differential Display PCR is crucial to minimize false-positive bands. To do this, we used quantitative real-time PCR that required relatively low quantities of RNA suitable for our study involving limited samples of human tissues. In skeletal muscle tissues 
of 50 non-diabetic Pima subjects, including eight subjects from the differential display experiment, we analyzed mRNA expression concentrations of selected 17 genes and ESTs. Multiple regression analyses showed that the individual mRNA expression concentrations of five genes (DD23, ATP1A2, PRPSAP1, MAP2K4, and MTND4) are associated with several in vivo measures of insulin resistance of the donors [glucose disposal rates at physiologic (M-low) and maximally stimulating (M-high) insulin concentrations during clamp, as well as fasting plasma insulin concentration] independent of age, sex, and percent body fat. Some of the correlations between the gene expression concentrations and M-low were not present for the M-high correlations, presumably because the correlations were modest, and also because M-low and M-high measure slightly different aspects of insulin action in vivo. The validation rate of $29 \%$ might reflect not only the methodological differences between DDPCR and Real Time PCR, but also grouping differences between the six paired subjects for DDCPR and the extension sample set of 50 subjects.

This study was conducted to complement our previous microarray data on skeletal muscle gene expression in non-diabetic insulin-resistant compared with insulin-sensitive Pima Indians using microarray [9]. Out of the 13 known genes differentially expressed in the DDPCR experiment, five were not arrayed on the Hu6800 arrays used in the previous study. In fact, one of the five genes, MTND4, turned out to be correlated to fasting plasma insulin in the extension sample set of this study. This result showed the utility of DDPCR in complementing microarrays that have defined sets of genes/ESTs to interrogate. Nevertheless, the other genes that correlated with measures of insulin sensitivity in the extension sample set of this study were not differentially expressed in the microarray data. Closer analysis showed that the microarray expression concentrations (average difference) of probe sets interrogating all of these genes, except $A T P 1 A 2$, were below reliable detection level. The failure of microarray to identify the moderately abundant ATP $1 A 2$ muscle transcript as differentially expressed might represent a false negative case, which proved to be positive using DDPCR. Despite these advantages of DDPCR, the procedure is more time consuming than microarray method, as also reported by another study [18], and could be less amiable to technical improvement than microarrays.

One of the validated genes with differential expression in our study, DD23, represents a novel susceptibility gene for insulin resistance in muscle; increased transcript concentration of this EST correlates not only with insulin resistance measured as lower glucose disposal rates during hyperinsulinaemic euglycaemic clamp, but also with higher fasting plasma concentration of insulin. A current database search (as of 11/02) indicated that DD23 shares homology with a few ESTs (accession numbers BG542139, AW298235, AI379723), although none of these ESTs correspond to any known gene. DD23 does not seem to code for any peptide homologous to any known proteins. An in silico search placed the gene encoding DD23 on chromosome 3p, which has suggestive linkages to fasting plasma insulin concentration in Pima Indians [19]. This chromosomal region also showed linkage to fasting C-peptide/glucose concentration in the FUSION study [20]. Taken together, these results warrant further investigation on the identity of DD23 and its role in insulin sensitivity.

Insulin sensitivity was also negatively associated with skeletal muscle mRNA concentrations of ATP1A2 independent of age, sex, and percent body fat. The ATP1A2 gene encodes the $\alpha 2$ subunit of $\mathrm{Na}^{+} / \mathrm{K}^{+}$-ATPase, which is specifically expressed in skeletal muscle, heart and fat tissues [21]. Several isoforms of $\mathrm{Na}^{+} / \mathrm{K}^{+}$-ATPase exist from different combinations of the $\alpha$ and $\beta$ subunits [22]. In the streptozotocin (STZ) rat model of diabetes, increased muscle $\alpha 2$ subunit mRNA [23] and protein concentrations [24] with no change or decrease of enzyme activity were observed in skeletal muscle. The increase in $\alpha 2$ mRNA concentration was thought to be a compensatory increase due to the decreased $\mathrm{Na}^{+} / \mathrm{K}^{+}$-ATPase activity under hypoinsulinaemic state, which occurred in the STZ-induced diabetes or after 48-h fasting in rats [23]. The skeletal muscle mRNA expression of ATP1A2 could respond similarly to hypoinsulinaemic and insulin-resistant states. Furthermore, $\alpha 2$ subunit mRNA expression was increased by long-term insulin treatment of 3T3-L1 cells [22, 25]; the treatment presumably induced insulin resistance $[26,27]$. Thus, the increased skeletal muscle mRNA expression of ATP1A2 in insulin-resistant subjects of this study might be a secondary effect of insulin resistance. Nevertheless, we cannot exclude the possibility that polymorphisms in the ATP1A2 gene might be the primary cause for insulin resistance. This gene maps to chromosome 1q21-23, a region previously reported to be linked to insulin resistance and Type 2 diabetes in Pima Indians [28], French population [29], and Utah Caucasians [30]. Thus, the ATP1A2 gene can still be considered as a candidate susceptibility gene for insulin resistance.

Our results indicate that insulin resistance is also correlated with increased skeletal muscle mitogen-activated protein kinase kinase 4 (MAP2K4). MAP2K4 is a member of mitogen-activated protein kinase (MAPK) family generally involved in the regulation of cell growth, differentiation, and survival [31]. Insulin increases glucose uptake by initially increasing glucose transporter (GLUT4) translocation to cell surface and then further activating the transporters. This GLUT4 activation seems to be regulated by a p38 MAPK (MAPK14)-dependent signalling pathway [32], which acts downstream of MAP2K4 [33]. Thus, 
it is possible that the increased mRNA expression of MAP2K4 in skeletal muscle of insulin-resistant subjects in this study constitutes a compensatory mechanism to counter against the insulin-resistant condition of the tissue.

Fasting plasma insulin concentration (adjusted for age, sex, and percent body fat) was correlated with skeletal muscle transcript concentration of NADH dehydrogenase 4 (MTND4). MTND4 is encoded by the guanine-rich heavy $(\mathrm{H})$ strand of the mitochondrial genome and located between nucleotide pair 10760 and 12137 [34]. It is one of subunits of NADH-ubiquinone oxidoreductase (respiratory complex I) that transports electrons from NADH to ubiquinone. We observed decreased MTND4 transcript concentration in muscle of non-diabetic insulin-resistant Pima Indians, whereas it was previously reported to be upregulated in skeletal muscle tissues of human subjects with Type 1 or Type 2 diabetes despite decreased mitochondrial DNA copy number [35]. We do not have any data on mitochondrial DNA copy number in our study, but the decreased expression of MTND4 transcript concentration in non-diabetic insulin-resistant subjects could reflect lower gene copy number. One can speculate that if subsequent diabetes is uncontrolled, the mRNA expression of MTND4 and perhaps other mitochondrially encoded genes of the oxidative phosphorylation pathway are increased to compensate for the decreased copy number, resulting in increased mitochondrial respiration.

Another gene transcript increased in insulin-resistant subjects codes for phosphoribosyl pyrophosphate synthetase-associated protein 1 (PRPSAP1). This protein is a putative regulatory subunit of the phosphoribosylpyrophosphate (PRPP) synthetase complex, which catalyzes the formation of PRPP from ATP and ribose 5-phosphate. It might play a negative regulatory role in PRPP synthesis [36]. PRPSAP1 is encoded by a gene on chromosome 17q24-q25. The mechanistic details that might have resulted in the negative correlation of skeletal mRNA expression of PRPSAPI with insulin sensitivity still need to be further elucidated.

Distinguished banding patterns on differential display gels in our study led to the genotyping of MTCO2, RY-1 and DD34 cDNA bands. The polymorphic MTCO2 cDNA bands resulted from insertion/ eletion of a 9-base pair repeat sequence in position $8271-8290$ of the mitochondrial genome, which is common in Asians, Polynesian and Native Americans $[37,38,39]$. None of the genotyped polymorphisms were related to insulin sensitivity in the 50 Pima subjects. Our results point to the possibility that some cDNA products amplified by the degenerate differential display primers could appear to be differentially expressed, when, in fact, the absence of such amplicons in particular samples are due to an insertion/ deletion mutation within the amplicon of differential display or to the inability of the primers to bind to the template if the primer binding sites are polymorphic.

In summary, we carried out differential display to identify differential gene expression associated with insulin resistance in non-diabetic Pima Indians. We identified 29 unique, differentially expressed transcripts and sought to validate 17 of them with quantitative real-time PCR in 50 subjects. Multiple regression analyses showed that the mRNA expression concentrations of DD23, ATP1A2, MAP2K4, MTND4, and PRPSAP1 are associated with glucose disposal rate at physiological and maximally stimulating insulin concentration during clamp and fasting plasma insulin concentration of the donors independent of age, sex, and percent body fat. These differentially expressed muscle transcript concentrations might contribute to or result from the development of insulin resistance prior to frank diabetes. Thus, the genes encoding the aforementioned transcripts serve as candidate susceptibility genes for insulin resistance.

Acknowledgements. We would like to thank the members and leaders of the Gila River Indian Community, without whose cooperation these studies would have been impossible. We gratefully acknowledge M. Milner, PA, C. Massengill, RN, the nurses of the clinical research ward, and the metabolic kitchen staff for the care of the research volunteers. We also thank G. Luczy-Bachman for technical help.

\section{References}

1. Bogardus C (1996) Metabolic abnormalities in the development of non-insulin dependent diabetes mellitus. In: LeRoith D, Taylor SI, Olefsky JM (eds) Diabetes mellitus: a fundamental and clinical text. Lippincott Williams \& Wilkins, Philadelphia, pp 459-467

2. Knowler WC, Bennett PH, Hamman RF et al. (1978) Diabetes incidence and prevalence in Pima Indians: a 19-fold greater incidence than in Rochester, Minnesota. Am J Epidemiol 108:497-505

3. Lillioja S, Mott DM, Spraul M et al. (1993) Insulin resistance and insulin secretory dysfunction as precursors of non-insulin-dependent diabetes mellitus. Prospective studies of Pima Indians. N Engl J Med 329:1988-1992

4. Knowler WC, Pettitt DJ, Saad MF et al. (1991) Obesity in the Pima Indians: its magnitude and relationship with diabetes. Am J Clin Nutr 53:1543S-1551S

5. Hillier TA, Pedula KL (2001) Characteristics of an adult population with newly diagnosed type 2 diabetes: the relation of obesity and age of onset. Diabetes Care 24:15221527

6. Bogardus C, Lillioja S, Mott DM et al. (1985) Relationship between degree of obesity and in vivo insulin action in man. Am J Physiol 248:E286-E291

7. Lillioja S, Mott DM, Zawadzki JK et al. (1987) In vivo insulin action is familial characteristic in nondiabetic Pima Indians. Diabetes 36:1329-1335

8. DeFronzo RA, Bonadonna RC, Ferrannini E (1992) Pathogenesis of NIDDM. A balanced overview. Diabetes Care 15:318-368 
9. Yang X, Pratley RE, Tokraks S et al. (2002) Microarray profiling of skeletal muscle tissues from equally obese, non-diabetic insulin-sensitive and insulin-resistant Pima Indians. Diabetologia 45:1584-1593

10. Tataranni PA, Ravussin E (1995) Use of dual-energy X-ray absorptiometry in obese individuals. Am J Clin Nutr 62:730-734

11. Alberti KG, Zimmet PZ (1998) Definition, diagnosis and classification of diabetes mellitus and its complications. Part 1: diagnosis and classification of diabetes mellitus provisional report of a WHO consultation. Diabet Med 15:539-553

12. Weyer C, Bogardus C, Mott DM et al. (1999) The natural history of insulin secretory dysfunction and insulin resistance in the pathogenesis of type 2 diabetes mellitus. J Clin Invest 104:787-794

13. Bogardus C, Lillioja S, Howard BV et al. (1984) Relationships between insulin secretion, insulin action, and fasting plasma glucose concentration in nondiabetic and noninsulin-dependent diabetic subjects. J Clin Invest 74:12381246

14. Lillioja S, Bogardus C (1988) Obesity and insulin resistance: Lessons learned from the Pima Indians. Diabet Metab Rev 4:517-540

15. Majer M, Mott DM, Mochizuki H et al. (1996) Association of the glycogen synthase locus on 19q13 with NIDDM in Pima Indians. Diabetologia 39:314-321

16. Liang P, Pardee AB (1992) Differential display of eukaryotic messenger RNA by means of the polymerase chain reaction. Science 257:967-971

17. Alway SE, Degens H, Lowe DA et al. (2002) Increased myogenic repressor Id mRNA and protein levels in hindlimb muscles of aged rats. Am J Physiol Regul Integr Comp Physiol 282:R411-R422

18. Higuchi E, Oridate N, Furuta Y et al. (2003) Differentially expressed genes associated with CIS-diamminedichloroplatinum (II) resistance in head and neck cancer using differential display and CDNA microarray. Head Neck 25:187-193

19. Pratley RE, Thompson DB, Prochazka M et al. (1998) An autosomal genomic scan for loci linked to prediabetic phenotypes in Pima Indians. J Clin Invest 101:17571764

20. Watanabe RM, Ghosh S, Langefeld CD et al. (2000) The Finland-United States investigation of non-insulin-dependent diabetes mellitus genetics (FUSION) study. II. An autosomal genome scan for diabetes-related quantitativetrait loci. Am J Hum Genet 67:1186-1200

21. Lingrel JB (1992) Na,K-ATPase: isoform structure, function, and expression. J Bioenerg Biomembr 24:263-270

22. Sweeney G, Klip A (1998) Regulation of the Na+/K+ATPase by insulin: why and how? Mol Cell Biochem 182:121-133

23. Nishida K, Ohara T, Johnson J et al. (1992) $\mathrm{Na}+/ \mathrm{K}(+)-$ ATPase activity and its alpha II subunit gene expression in rat skeletal muscle: influence of diabetes, fasting, and refeeding. Metabolism 41:56-63

24. Ng YC, Tolerico PH, Book CB (1993) Alterations in levels of $\mathrm{Na}(+)-\mathrm{K}(+)$-ATPase isoforms in heart, skeletal muscle, and kidney of diabetic rats. Am J Physiol 265:E243-E251
25. Russo JJ, Sweadner KJ (1993) Na(+)-K(+)-ATPase subunit isoform pattern modification by mitogenic insulin concentration in 3T3-L1 preadipocytes. Am J Physiol 264:C311C316

26. Maier VH, Gould GW (2000) Long-term insulin treatment of 3T3-L1 adipocytes results in mis- targeting of GLUT4: implications for insulin-stimulated glucose transport. Diabetologia 43:1273-1281

27. Berg CE, Lavan BE, Rondinone CM (2002) Rapamycin partially prevents insulin resistance induced by chronic insulin treatment. Biochem Biophys Res Commun 293:1021-1027

28. Hanson RL, Ehm MG, Pettitt DJ et al. (1998) An autosomal genomic scan for loci linked to type II diabetes mellitus and body-mass index in Pima Indians. Am J Hum Genet 63:1130-1138

29. Vionnet N, Hani E, Dupont S et al. (2000) Genomewide search for type 2 diabetes-susceptibility genes in French whites: evidence for a novel susceptibility locus for earlyonset diabetes on chromosome 3q27-qter and independent replication of a type 2-diabetes locus on chromosome 1q21-q24. Am J Hum Genet 67:1470-1480

30. Elbein SC, Hoffman MD, Teng K et al. (1999) A genomewide search for type 2 diabetes susceptibility genes in Utah Caucasians. Diabetes 48:1175-1182

31. Seger R, Krebs EG (1995) The MAPK signaling cascade. FASEB J 9:726-735

32. Somwar R, Kim DY, Sweeney G et al. (2001) GLUT4 translocation precedes the stimulation of glucose uptake by insulin in muscle cells: potential activation of GLUT4 via p38 mitogen- activated protein kinase. Biochem J 359:639649

33. Guan Z, Buckman SY, Pentland AP et al. (1998) Induction of cyclooxygenase- 2 by the activated MEKK $1 \rightarrow$ SEK1/ $\mathrm{MKK} 4 \rightarrow \mathrm{p} 38$ mitogen-activated protein kinase pathway. J Biol Chem 273:12901-12908

34. Anderson S, Bankier AT, Barrell BG et al. (1981) Sequence and organization of the human mitochondrial genome. Nature 290:457-465

35. Antonetti DA, Reynet C, Kahn CR (1995) Increased expression of mitochondrial-encoded genes in skeletal muscle of humans with diabetes mellitus. J Clin Invest 95:1383-1388

36. Kita K, Ishizuka T, Ishijima S et al. (1994) A novel 39-kDa phosphoribosylpyrophosphate synthetase-associated protein of rat liver. Cloning, high sequence similarity to the catalytic subunits, and a negative regulatory role. J Biol Chem 269:8334-8340

37. Wrischnik LA, Higuchi RG, Stoneking M et al. (1987) Length mutations in human mitochondrial DNA: direct sequencing of enzymatically amplified DNA. Nucleic Acids Res 15:529-542

38. Hertzberg M, Mickleson KN, Serjeantson SW et al. (1989) An Asian-specific 9-bp deletion of mitochondrial DNA is frequently found in Polynesians. Am J Hum Genet 44:504-510

39. Schurr TG, Ballinger SW, Gan YY et al. (1990) Amerindian mitochondrial DNAs have rare Asian mutations at high frequencies, suggesting they derived from four primary maternal lineages. Am J Hum Genet 46:613-623 